\title{
Physicochemical Properties of Potential Low-Temperature Drilling Fluids for Deep Ice Core Drilling
}

\author{
Ning Liu ${ }^{1}$, Huiwen $\mathrm{Xu}^{1}$, Yang Yang${ }^{1}$, Lili Han², Lili Wang${ }^{1}$, Pavel Talalay ${ }^{1}$ \\ 1Polar Research Center, Jilin University, Changchun Jilin 130026, China \\ 2The Institute of Exploration Techniques, CAGS, Langfang Hebei 065000, China \\ Correspondence to: ptalalay@yahoo.com
}

\begin{abstract}
Drilling fluids are added to deep ice boreholes to facilitate control pressure and remove chips. The drilling fluids currently in use are not intelligent choices for the future from safety, environmental, and technological standpoints. Two potential fluid types, namely, low-molecular weight dimethylsiloxane oils (DSOs) and low-molecular-weight fatty-acid esters (FAEs), were suggested to replace the drilling fluids currently in use. For this study, six types of liquids (DSO-3,0cs, KF96-2,0cs, ethyl butyrate, $n$-propyl propionate, $n$-butyl butyrate, and $n$-amyl butyrate) were selected because of their appropriate densityviscosity properties. These liquids were tested for properties such as electrical conductivity, thermal conductivity, and compatibility with plastics. The results indicated that the electrical conductivities of all the liquids were very small $(<0.003 \mu \mathrm{S} / \mathrm{cm})$, and an electric field applied in the electromechanical drills was not sufficient to ionize the liquid. The thermal conductivities of all the tested liquids were considerably less than that of water. However, $n$-propyl propionate indicated the best performance in terms of the cooling ability at subzero temperatures. The effect of FAEs on 0-rings swelling was stronger than that of the DSOs. The potential drilling fluids had absolutely no influence on polytetrafluoroethylene (PTFE) O-rings; hence, they could be considered as the ideal sealing material. Tests indicated that low-molecular-weight DSOs and FAEs were both applicable as drilling fluids for deep ice core drilling. It is suggested that the final decision should be confirmed by field-based and practical experiments in test boreholes.
\end{abstract}




\section{Introduction}

Drilling fluid is one of the main components of deep ice core drilling technology. There are two basic functions of a drilling fluid (Talalay et al., 2014a). First, the presence of a densitybalanced fluid in the hole prevents the hole from closing because of Newtonian-plastic deformations. Second, the circulation of the fluid in the borehole provides a mechanism for the transportation of cuttings from the drill head to the downhole chamber or to the surface. Past studies indicate several choices of low-temperature drilling fluids such as kerosene-based fluids, ethanol and $n$-butyl acetate. However, not all these fluids qualify as intelligent choices from the perspectives of safety, environment, and technology (Talalay et al., 2014b). Therefore, the selection of an appropriate drilling fluid for coring in deep ice is a pressing problem for future drilling projects.

Recently, aliphatic synthetic ester ESTISOL ${ }^{\mathrm{TM}} 140$ was introduced as a good alternative to existing drilling fluids (Sheldon et al., 2014; Talalay et al., 2014b). ESTISOL ${ }^{\mathrm{TM}} 140$ has appropriate density-viscosity properties and is not considered as hazardous. Over the last few years, ESTISOL ${ }^{\mathrm{TM}} 140$ was used at NEEM, Greenland (2012); Aurora Basin North, East Antarctica (2013-14); Summit, Greenland (2014); Renland Ice Cap, Greenland (2015); and more recently at the South Pole (2014-15 and 2015-16 seasons). Generally, ESTISOL ${ }^{\mathrm{TM}}$ 140 was as an acceptable drill liquid that consistently produced good quality ice cores. However, tests in Greenland conducted by researchers from the University of Wisconsin, Madison in the summer of 2014 revealed that the drilling fluid released strong vapors even at subzero temperatures. Furthermore, the drilling fluid had toxic and irritant effects (J. Johnson, pers. comm., 2014). The side effects experienced by personnel during drilling included headaches, lightheadedness, throat/lung irritation, eye irritation, skin dryness, 
and mild stomach aches. Similar toxic and irritant effects of ESTISOL ${ }^{\mathrm{TM}} 140$ on drilling personnel were recorded at the South Pole (T. Kuhl, pers. comm., 2015).

Therefore, the identification of a non-toxic, non-flammable, density appropriate, hydrophobic, inexpensive, environmentally friendly, and readily available fluid with predictable performance characteristics is still a major challenge of the ice core drilling technology. Talalay (2007) and Xu et al. (2014) discussed two potential fluid types, namely low-molecular-weight dimethylsiloxane oils (DSOs) and low-molecular-weight fatty-acid esters (FAEs) in considerable detail. However, the final decision on the application of these fluids for ice core drilling depended on conducting additional lab tests and field experiments in a test borehole.

DSOs are clear, colorless, tasteless, odorless, hydrophobic, and essentially inert liquids that are stable in contact with water, air, oxygen, metals, wood, paper, and plastics. Although there are several DSOs, the low-viscosity grades $\left(<5 \mathrm{~mm}^{2} \mathrm{~s}^{-1}\right)$ of silicones (e.g., KF96-1,5cs and KF96-2,0cs) are the closest match to the requirements for a drilling fluid (Triest and Alemany, 2014). Some of DSOs, namely PMX200 from Dow Xiameter, have exposure limits; however, most of DSOs have no specifications on the air contamination levels. Thus, there are no recommendations for the control of workplace contamination concentrations. ShinEtsu Chemical Co., a DSOs manufacturer, reported on the potential hazard of DSOs to human health. Eye contact with low-molecular DSOs led to temporary irritations. However, no permanent harm to eyes was reported.

FAEs are another example of promising low-temperature drilling fluids. They are typically fragrant. FAEs with a sufficiently low molecular weight have appropriate volatility for application in fragrances. FAEs are often part of "essential oils" and pheromones. The chemically synthesized FAEs have found commercial applications in artificial flavorings, because they resemble certain flavorings (for example orange or pineapple juice) and 
within certain limitations are harmless to the human body if ingested. The following five non-HAP (i.e., not listed as hazardous air pollutants), low-molecular-weight FAEs could be considered for use as low-temperature drilling fluids for deep ice coring: ethyl butyrate, $n$ propyl propionate, $n$-butyl butyrate, $n$-amyl butyrate, and hexyl acetate. According to the available data, these FAEs are not hazardous to human health.

The density-viscosity tests (Talalay, 2007; Triest and Alemany, 2014; Xu et al., 2014) demonstrated that only a small number of DSOs and FAEs meet the ice-drilling requirements. Furthermore, some of the physicochemical properties of these liquids were unknown and require further clarification before conducting practical experiments in the test boreholes. The drilling fluid was required to exhibit low electrical conductivity in order to avoid interference with the operation of non-sealed electrical and electronic components such as slip rings, contacts, electric sensors, and motors. The drilling fluid should be nonaggressive to the drill components. This is especially applicable as 0-rings and gaskets can swell, soften, or become tacky in fluid. Additionally, the thermal conductivity of the drilling fluid could influence the drilling process. For example, in "warm ice" (Augustin et al., 2007), liquids with high thermal conductivities could absorb the cutting heat produced by the drill head and improve drilling performance. This paper investigated electrical conductivities, thermal conductivities, and effect on plastics of DSOs and FAEs.

\section{Electrical conductivity}

Most ice core electromechanical drills have a number of non-sealed electrical and electronic components that considerably increase the ease of design and service. Many of the drill electronic sensors are designed to work directly in non-conductive or very poorly conductive drilling fluids. For example, drilling load is usually measured with simple linear displacement sensors located in the cable termination of the drills. Driven motors of some 
of the drills (e.g., KEMS drill) are not hidden in the pressure chamber and are immersed into the drilling fluid. Not all downhole electric connectors for signal and power communication are also not appropriate for use in conductive fluids. Evidently, the electric conductivity of the drilling fluid can influence the operation capacity of the downhole drill components.

The electrical conductivity of fluid depends upon the number of ions per unit volume and the drift velocities of the ions. The drift velocity of an ion varies with the electric field intensity, the mass of the ion, and other factors. Thus, the electrical conductivities of different fluids can have a range of values. Electric conductivity is a factor of temperature, and this affects ion mobility. In this regard, the conductivity of fluids generally decreases as temperature decreases.

According to the US National Fire Protection Association "Recommended Practice on Static Electricity" (NFPA 77, 2014), liquids having conductivities $>10^{-4} \mu \mathrm{S} / \mathrm{cm}$ are classified as conductive. Liquids with conductivity less than $10^{-6} \mu \mathrm{S} / \mathrm{cm}$ are generally considered to be non-conductive. Liquids having conductivities between these values are classified as medium-conductive.

Kerosenes that were mostly used as bases of low-temperature drilling fluids in the past are medium-conductive liquids with conductivities of $\sim 3 \times 10^{-6} \mu \mathrm{S} / \mathrm{cm}$ (Dey, 2004). Even conductive liquids like $n$-butyl acetate $(0.02 \mu \mathrm{S} / \mathrm{cm}$ at room temperature; Flammability: A safety guide for users, 2013) were successfully used as drilling fluids because the electric fields in the drills were considerably small and, therefore, could not ionize the liquid. Thus, conductive liquids could also be used as drilling fluids up to a certain safety threshold. The estimation of the threshold requires additional tests on the applied electric field, temperature, impurities, and other factors. Water-based liquids (e.g., aqueous ethanol 
solutions) with conductivities $>50-100 \mu \mathrm{S} / \mathrm{cm}$ cannot be used as drilling fluids with drills containing non-sealed electric components.

This study measured the electrical conductivities of six selected drilling fluid types (DSO3,0cs produced at Shanghai Kaiping Resin Factory; KF96-2,0cs produced by Shin-Etsu Chemical Co.; ethyl butyrate, $n$-propyl propionate, $n$-butyl butyrate, and $n$-amyl butyrate) in a temperature range from $-60^{\circ} \mathrm{C}$ to $0^{\circ} \mathrm{C}$ with intervals of $5^{\circ} \mathrm{C}$. General properties of selected fluids are listed in Table 1. Leici tester DDSJ-308F that could measure the conductivities of different mediums in the range of $0.001-199.9 \mu \mathrm{S} / \mathrm{cm}$ with an error of $\pm 0.5 \%$ (Fig. 1 ) was used. A conductivity electrode DJS-0.01C with a narrower measuring range of $0.001-2.0$ $\mu \mathrm{S} / \mathrm{cm}$ was used for the testing. The tested liquid was poured into the cup of a lowtemperature thermostat of DC-6506 type produced by Fangrui Instrument Co Ltd., Shanghai. At subzero temperatures, the electric conductivities of all fluids were less than the tester sensitivity $\left(10^{-3} \mu \mathrm{S} / \mathrm{cm}\right)$. At positive temperatures $\left(25^{\circ} \mathrm{C}\right)$, the electrical conductivities of only two liquids, namely ethyl butyrate and $n$-propyl propionate, were recorded as $0.003 \mu \mathrm{S} / \mathrm{cm}$ and $0.002 \mu \mathrm{S} / \mathrm{cm}$, respectively.

Then, the electrical conductivity of the drilling fluid/ice-chips mixture was tested. The mixture was considered as a homogeneous fluid with mean physical properties that correctly characterized the real solid/liquid suspension. Ice chips were prepared by cooling water drops with an average volume of $10-20 \mathrm{~mm}^{3}$ in the drilling fluid to a temperature of $-60^{\circ} \mathrm{C}$ in a freezing chamber. Two sets of experiments were carried out with different concentration of ice chips. The experiment involved adding $16 \mathrm{~cm}^{3}$ and $48 \mathrm{~cm}^{3}$ of ice that was made into chips to $350 \mathrm{ml}$ of the fluid, attaining ice volumetric contents of $4.6 \%$ and 13.7\%, respectively. Then, the electrical conductivities of the drilling-fluid/ice-chips mixtures were measured in a temperature ranging from $-60{ }^{\circ} \mathrm{C}$ to $0^{\circ} \mathrm{C}$ (Fig. 2). 
At temperatures less than $-15^{\circ} \mathrm{C}$, conductivities of all tested drilling-fluid/ice-chips mixtures were less than the sensitivity of the tester and were not affected by the ice content. At the temperature range from $-15^{\circ} \mathrm{C}$ to $-5^{\circ} \mathrm{C}$, the electrical conductivities were potentially recorded because a liquid layer was developed on the surface of the ice chips and along the crystal boundaries. Temperature increases led to changes in the grain boundaries. The grain boundaries increased in width, were more disordered, and the amount of liquid water contained in the grain boundaries increased with an increase in temperature (Cuffey and Patterson, 2010). As a result, the electrical conductivities began to increase at a temperature of $-5^{\circ} \mathrm{C}$ and the electrical conductivities experienced a sharp jump at the phase-transition temperature $\left(0^{\circ} \mathrm{C}\right)$.

The electrical conductivities of the DSO/ice-chips mixtures exceeded the electrical conductivities of the $\mathrm{FAE} /$ ice-chips mixtures. At $0^{\circ} \mathrm{C}$ and $4.6 \%$ ice content, the electrical conductivity of DS0-3,0cs was the highest at $0.256 \mu \mathrm{S} / \mathrm{cm}$. This was followed by KF96-2,0cs silicone oil at $0.085 \mu \mathrm{S} / \mathrm{cm}$. The conductivities of all tested FAEs were less than 0.032 $\mu \mathrm{S} / \mathrm{cm}$.

As the ice concentration increased in the fluid, the amount of the liquid water also increased. Thus, the conductivities of drilling-fluid/ice-chips mixtures increased. At $0^{\circ} \mathrm{C}$ and $13.7 \%$ ice content, the conductivity of DS0-3,0cs increased to $0.385 \mu \mathrm{S} / \mathrm{cm}$. This was followed by propyl propionate and KF96-2,0cs silicone oil at $0.197 \mu \mathrm{S} / \mathrm{cm}$ and 0.166 $\mu \mathrm{S} / \mathrm{cm}$, respectively. The conductivities of the other mixtures were less than $0.02 \mu \mathrm{S} / \mathrm{cm}$.

Hence, at temperatures less than $-5{ }^{\circ} \mathrm{C}$, the conductivities of all tested drilling fluids and drilling-fluid/ice-chips mixtures were quite small $(<0.02 \mu \mathrm{S} / \mathrm{cm})$, and could be considered safe for drilling with non-sealed electric components. However, at temperatures close to melting point, (for example drilling in the warm ice) the presence of ice chips rapidly raised 
the drilling fluid conductivity. This should be taken into account in the drilling process planning.

\section{Thermal conductivity}

The effect of the thermal conductivity of drilling fluids on the cooling ability of the drill head is crucially important for drilling in the warm ice. Drilling of the warm ice was extremely difficult with electromechanical drills because as the drill penetrated, refrozen ice started to build up on the cutters and shoes of the drill head. Hence, the performance of the drill rapidly deteriorated to a point where the penetration stopped. There were several attempts to solve the icing problems but the ultimate solution was not found (Talalay et al., 2015). An icing-mitigation method takes advantage of the physical properties of the drilling fluid. Generally, the drilling fluid used in ice drilling should have a thermal conductivity as high as possible.

Additionally, the thermal conductivity of the drilling fluid is influencing the time of thermal stabilization of the borehole. This is needed for precise temperature measurements. Borehole temperature measured during drilling or soon after the termination of drilling varies from the true temperature of the ice mass. This is because heating from the downhole drill/cable and mixing during the movement of the drill in the hole disturbs the temperature pattern of the drilling fluid. The precise temperature measurements could be performed only after absolute thermal relaxation. This in turn depends on the initial thermal disturbance and thermal conductivity of the drilling fluid.

Thermal conductivities of selected drilling fluids were measured using a DRE-III tester with a measurement range of $0.005-100 \mathrm{~W} /(\mathrm{m} \cdot \mathrm{K})$, and a relative error of $\leq 3 \%$ at temperatures between $-50^{\circ} \mathrm{C}$ to $20^{\circ} \mathrm{C}$ with an interval of $10^{\circ} \mathrm{C}$ (Fig. 3). The thermal conductivity 
decreased with the decrease in temperature (Fig. 4). It is known that conductivity depends on the polarity, density and molecular thermodynamic movements of the liquid. Given that all selected liquids are non-polar materials with very similar densities, the molecular thermodynamic movement mainly distinguished the conductivity. It stands to reason that the molecular thermodynamic movement weakened with the decrease in temperature.

The thermal conductivity of $n$-propyl propionate was the highest. The molecular weights of $n$-propyl propionate and ethyl butyrate were the same, but their structures were different and potentially the activity of $\alpha$-hydrogen in $n$-propyl propionate was higher. The molecular weights of ethyl butyrate, $n$-butyl butyrate and $n$-amyl butyrate increased in turn. Increases in the molecular weight led to longer molecular chains, and this in turn increased the distance between the molecules leading to smaller thermal motion abilities. Silicone oil has saturated covalent bonds between the atoms and the structure was stronger. Hence, the thermal conductivity of silicone oil is smaller than conductivities of the tested FAEs.

The thermal conductivities of all tested liquids were far less than that of water $(0.604$ $\mathrm{W} /(\mathrm{m} \cdot \mathrm{K})$ at $\left.20^{\circ} \mathrm{C}\right)$. However, $n$-propyl propionate was the best in terms of the cooling ability at subzero temperatures and it had the shortest time of borehole temperature relaxation.

\section{Compatibility with polymers}

It is difficult to find an aspect of drilling technology that is not affected by polymers. In static applications, 0-rings made from different elastomers are widely used as downhole drill components for sealing pressure chambers and casing connections. Dynamic applications include rotating motor/pump shafts. Special fiberglass or HDPE casing is 
generally used within standard ice-drilling technology procedures. Some parts of downhole drilling equipment (for example auger spirals) are usually produced from plastics. It is evident that the drilling fluid should have no effect on the various materials employed in the drill string.

In order to test the compatibility of O-rings with the new potential drilling fluids, four types of polymer materials, namely fluorine rubber, silicone rubber, polyurethane, PTFE, were exposed to selected types of DSOs and FAEs. The initial outer diameter of all the 0-rings was $20 \pm 0.2 \mathrm{~mm}$ with cross-sectional diameter $2 \mathrm{~mm}$. The swelling ability of the 0-rings swelling was estimated by the changes in the outer diameter at different temperatures $\left(-25^{\circ} \mathrm{C},-12.5^{\circ} \mathrm{C}, 0^{\circ} \mathrm{C}, 12.5^{\circ} \mathrm{C}\right.$, and $\left.25^{\circ} \mathrm{C}\right)$ every hour during $10 \mathrm{~h}$. Results of the outer diameter changes at temperatures $-25^{\circ} \mathrm{C},-12.5^{\circ} \mathrm{C}$, and $0^{\circ} \mathrm{C}$ are shown in Fig. 5 .

Fluorine rubber is a synthetic polymer elastomer with a main chain or side chain containing fluorine atoms. It is used in many applications to resist harsh chemical attacks. Increasing the fluorine content improves resistance to chemical attack, and diminishes low temperature characteristics. However, there are specialty grade fluorocarbons that could provide high fluorine content with low temperature properties. A fluorine rubber well resists silicone oils. Experiments showed that there were no visible changes in O-rings after immersion in DSO-3,0cs and KF96-2,0cs. However, the fluorine rubber significantly swelled in all the tested FAEs. 0-rings faster reached a stable state of swelling in ethyl butyrate and n-propyl propionate, after 6-8 h (Fig. 5a) and swelled less at negative temperatures (Fig. 6a).

Silicon rubber remains flexible down to very low temperatures $\left(-55^{\circ} \mathrm{C}\right)$. Nevertheless, tests revealed that 0-rings dramatically swelled in all tested drilling fluids (Fig. 5b and 6b) and, therefore, could not be used as drill components. The silicone rubber swelling was the most 
serious in silicone oils. This was potentially because the oil contained Si-O bonds similar to Si-O-Si bonds in the structure of silicone rubber.

Polyurethane is a macromolecular polymer composed of organic units joined by urethane (-NHCOO-) links. Due to the softer nature of urethane, the physical properties of this polymer could change with exposure to certain environmental conditions like temperature, humidity and UV radiation. The typical life expectancy of polyurethane products is approximately 5 years. Polyurethane 0-rings displayed considerable swelling in $n$-propyl propionate. This was followed by ethyl butyrate and $n$-butyl butyrate (Fig. 5c and 6c). Polyurethane 0 -rings did not swell in $n$-amyl butyrate at negative temperatures. Due to the large chemical differences between polyurethane and silicone oil, polyurethane did not react with DSO-3,0cs and KF96-2,0cs.

PTFE is only one polymer that did not react with the tested fluids. There were no changes in the diameter, cross-sectional diameter and mass of PTFE rings after immersion in the liquids under applied temperatures. The swelling rate of the other three types of polymers increased gradually with the increase in temperature and in most cases swelling stopped after immersion in drilling fluids for 6-8 $\mathrm{h}$.

\section{Conclusions}

The electric conductivities of selected DSOs and FAEs were very small $(<0.003 \mu \mathrm{S} / \mathrm{cm})$, and electric field applied in the electromechanical drills was evidently not sufficient to ionize the liquid. However, at temperatures close to melting point, the presence of ice chips rapidly raised the drilling fluid conductivity. This could lead to closed-circuit faults in the non-sealed electrical components. Hence, additional arrangements should be made if the drilling of the warm ice is planned. 
The influence of thermal conductivity on the drilling performance in cold and temperate ice was slight because the heat generated in the drill cutters was relatively small and could be effectively absorbed by the cold circulating fluid. In this regard, the small thermal conductivities of the selected DSOs and FAEs were non-essential. It is fair to assume that the cooling abilities of all the tested liquids were insufficient to absorb the heat generated while drilling in the warm ice. This assumption was indirectly confirmed during the drilling in the warm ice at depths deeper than $3000 \mathrm{~m}$ at Dome F in Antarctica. The drilling fluid used was $n$-butyl acetate and it had a thermal conductivity similar to the tested FAEs. It was observed by prior research that the core length frequently dropped as low as $\sim 10 \mathrm{~cm}$ in length (Motoyama, 2007).

The tests indicated that the effect of the FAEs on the swelling of the 0-rings was stronger than that of the DSOs. Polyurethane could be used as a sealing material in the case where silicone oils are used as drilling fluids. The potential drilling fluids had no influence on the PTFE 0-rings. Hence, the PTFE O-rings could be considered as the ideal sealing material. Usually, the PTFE sealing rings were used with fillers made from fiberglass, carbon, graphite, molybdenum disulfide, metal oxides, and various polymers. In most cases, unfilled PTFE provided a lower coefficient of friction than a filled PTFE material. It also provides the lowest degree of wear of the seal counter face. However, a sealing lip made of an unfilled PTFE material has limited resistance to wear and deformation under a load. Additional tests are required to check the compatibility of the filler with the drilling fluid if filled PTFE rings are planned for use in the downhole drill.

To summarize, low molecular weight DSOs and FAEs were both applicable as drilling fluids for deep ice core drilling. However, the final decision should be confirmed by field-based and practical experiments in test boreholes. 


\section{Acknowledgments}

This paper describes the research done under support of the National Science Foundation of China (Projects No. 41276189 and No. 41327804) and Ministry of Land and Resources of China (Project No. 201311041). We thank two anonymous reviewers for fruitful comments and advices.

\section{References}

Augustin, L., Motoyama, H., Wilhelms, F., Johnsen, S., Hansen, S.B., Talalay, P., Vasiliev, N. (2007). Drilling comparison in 'warm ice' and drill design comparison. Ann. Glaciol., 47, 73-78.

Cuffey, K.M., Paterson, W.S.B. (2010). The physics of glaciers, 4th edn. ButterworthHeinemann, Oxford.

Dey, W. (2004). Conductivity measurements for new engine compartment fluids. Chilworth Technology, Inc. Report R/4877/0404/WD.

Flammability: A safety guide for users (2013). Safe working with industrial solvents. Best Practice Guidelines 4, version 3, European Solvents Industry Group (ESIG).

Motoyama, H. (2007). The second deep ice coring project at Dome Fuji, Antarctica. Sci. Drilling, 5, 41-43.

NFPA 77 (2014). Recommended Practice on Static Electricity, US National Fire Protection Association.

Sheldon, S.G., Popp, T.J., Hansen, S.B., Steffensen, J.P. (2014). Promising new borehole liquids for ice-core drilling on the East Antarctic high plateau. Ann. Glaciol., 55(68), 260-270.

Talalay P.G. (2007). Dimethyl siloxane oils as an alternative bore-hole fluid. Ann. Glaciol., 47, 82-88.

Talalay, P.G., Fan, X., Xu, H., Yu, D., Han, L., Han, J., Sun, Y. (2014a). Drilling fluid technology in ice sheets: Hydrostatic pressure and borehole closure considerations. Cold Reg. Sci. Technol., 98, 47-54.

Talalay, P., Hu, Z., Xu, H., Yu, D., Han, L., Han, J., Wang L. (2014b). Environmental considerations of low-temperature drilling fluids. Ann. Glaciol., 55 (65), 31-40.

Talalay, P., Yang, C., Cao, P., Wang, R., Zhang, N., Fan, X., Yang, Y., Sun, Y. (2015). Ice-core drilling problems and solutions. Cold Reg. Sci. Technol., 120, 1-20.

Triest, J., Alemany, O. (2014). Drill fluid selection for the SUBGLACIOR probe: a review of silicone oil as a drill fluid. Ann. Glaciol., 55(68), 311-321.

Xu, H., Han, L., Cao, P., Guo, M., Han, J., Yu, D., Talalay, P. (2014). Low molecular weight, fatty acid esters as potential low-temperature drilling fluids for ice coring. Ann. Glaciol., 55 (68), 39-43. 
Table 1. General properties of selected fluids

\begin{tabular}{|l|c|c|c|c|c|c|}
\hline Properties & DSO-3,0cs & KF96-2,0cs & $\begin{array}{c}\text { Ethyl } \\
\text { butyrate }\end{array}$ & $\begin{array}{c}\text { n-Propyl } \\
\text { propionate }\end{array}$ & $\begin{array}{c}\text { n-Butyl } \\
\text { butyrate }\end{array}$ & $\begin{array}{c}n \text {-Amyl } \\
\text { butyrate }\end{array}$ \\
\hline CAS No. & $63148-62-9$ & $141-63-9$ & $105-54-4$ & $106-36-5$ & $109-21-7$ & $540-18-1$ \\
\hline Molecular formula & $\left(\mathrm{CH}_{3}\right)_{6} \mathrm{Si}_{2} \mathrm{O}$ & $\left(\mathrm{CH}_{3}\right)_{12} \mathrm{Si}_{5} \mathrm{O}_{4}$ & $\mathrm{C}_{6} \mathrm{H}_{12} \mathrm{O}_{2}$ & $\mathrm{C}_{6} \mathrm{H}_{12} \mathrm{O}_{2}$ & $\mathrm{C}_{8} \mathrm{H}_{16} \mathrm{O}_{2}$ & $\mathrm{C}_{9} \mathrm{H}_{18} \mathrm{O}_{2}$ \\
\hline Density*, $\mathrm{kg} / \mathrm{m}^{3}$ & 950 & 924 & 931 & 934 & 915 & 911 \\
\hline Viscosity*, $10^{-6} \mathrm{~m}^{2} \cdot \mathrm{s}^{-1}$ & 7.4 & 5.8 & 1.7 & 1.9 & 3.4 & 4.8 \\
\hline Freezing (pour) point, ${ }^{\circ} \mathrm{C}$ & -70 & -84 & -93.3 & -76.0 & -91.5 & -73.2 \\
\hline $\begin{array}{l}\text { Thermal conductivity* } \\
\text { W/(m-K) }\end{array}$ & 0.025 & 0.032 & 0.080 & 0.093 & 0.061 & 0.053 \\
\hline
\end{tabular}

${ }^{*} \mathrm{At}-30^{\circ} \mathrm{C}$ 


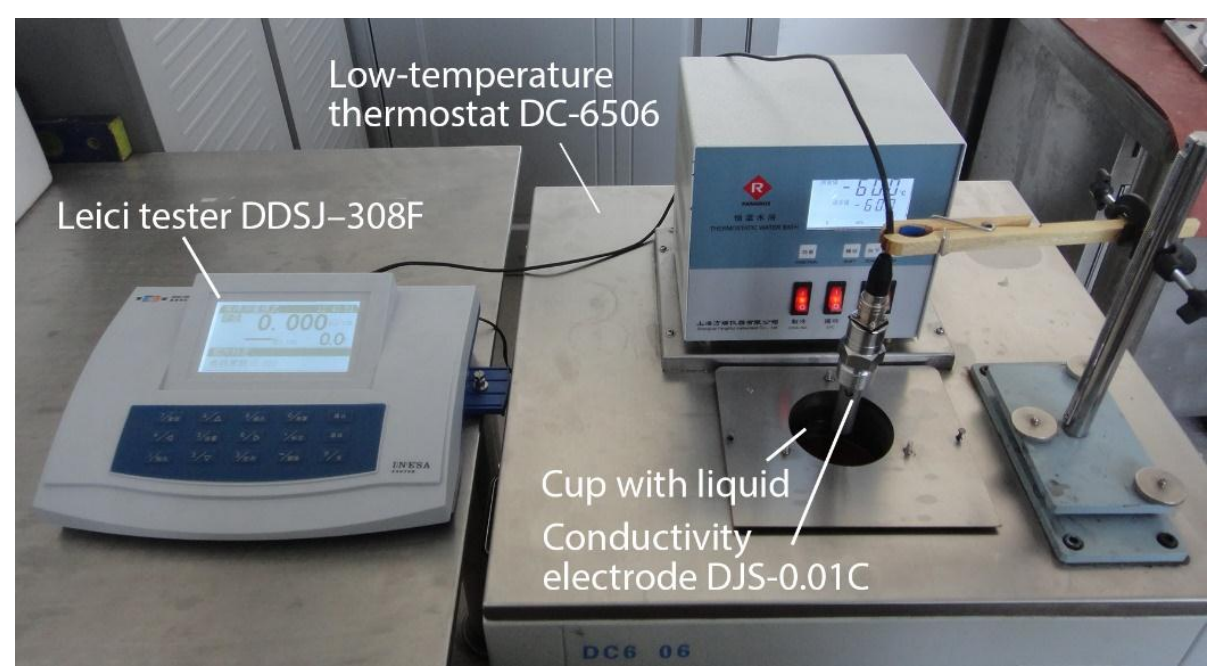

Fig. 1. Experimental setup for measuring electric conductivities 

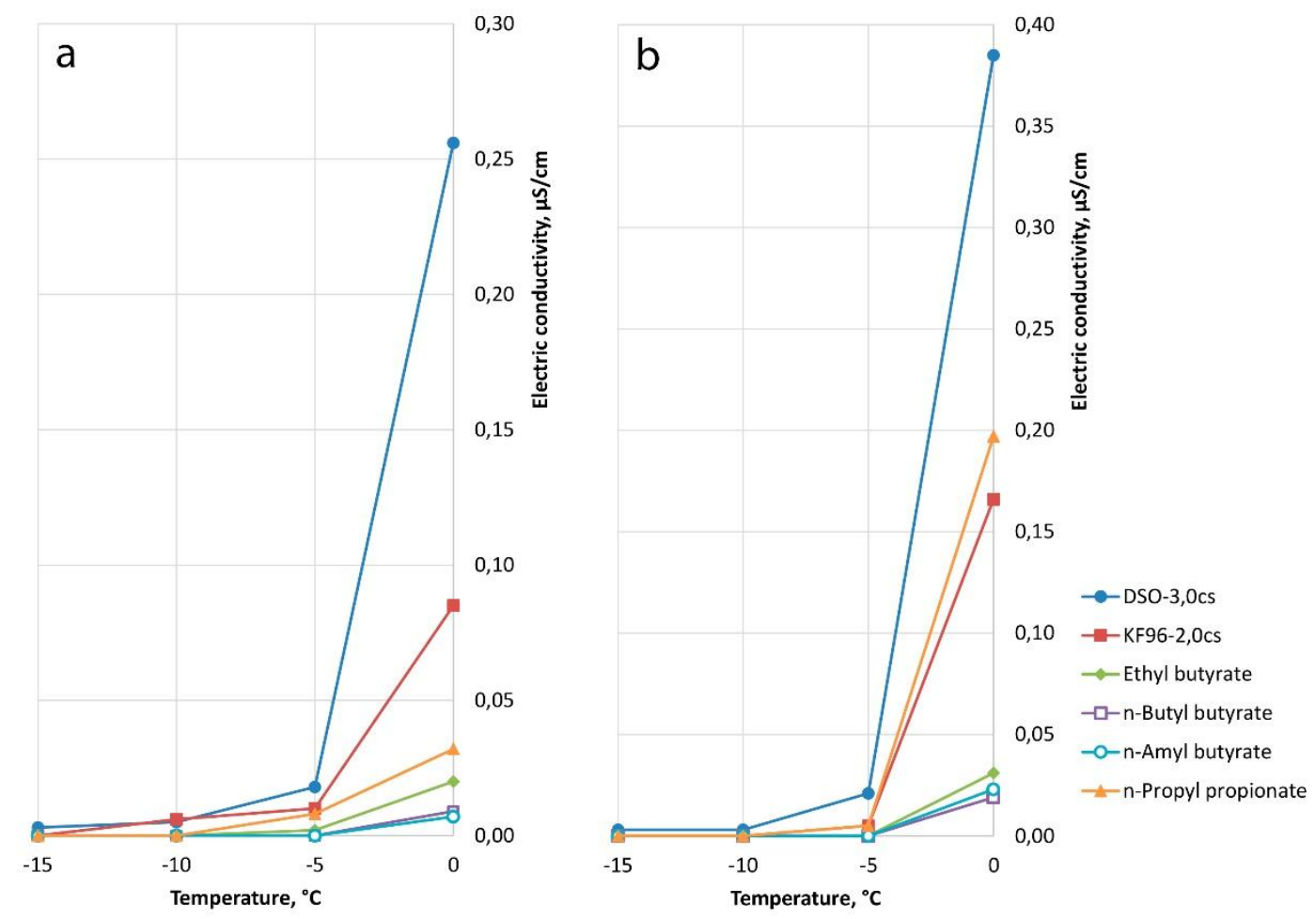

Fig. 2. Electric conductivities of drilling fluid/ice-chips mixtures vs temperatures with concentration of chips at $4.6 \%$ (a) and at $13.7 \%$ (b) 


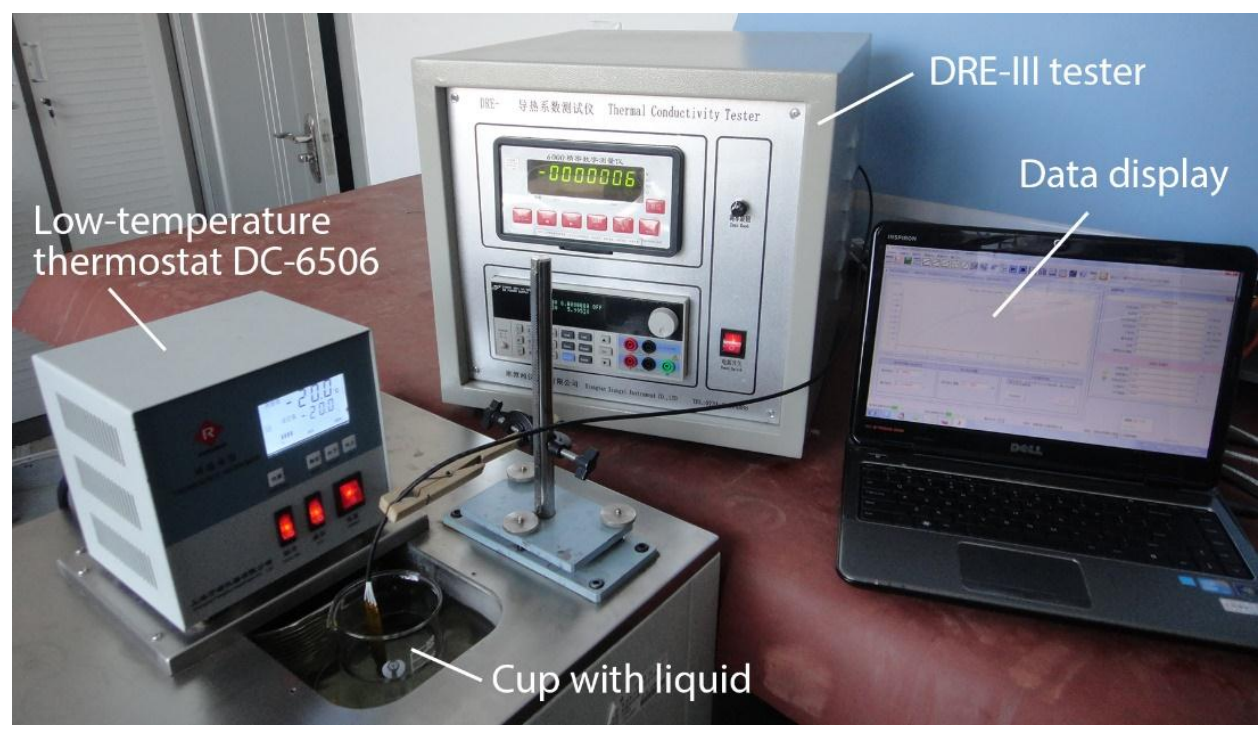

Fig. 3. The experimental setup for measuring thermal conductivities 


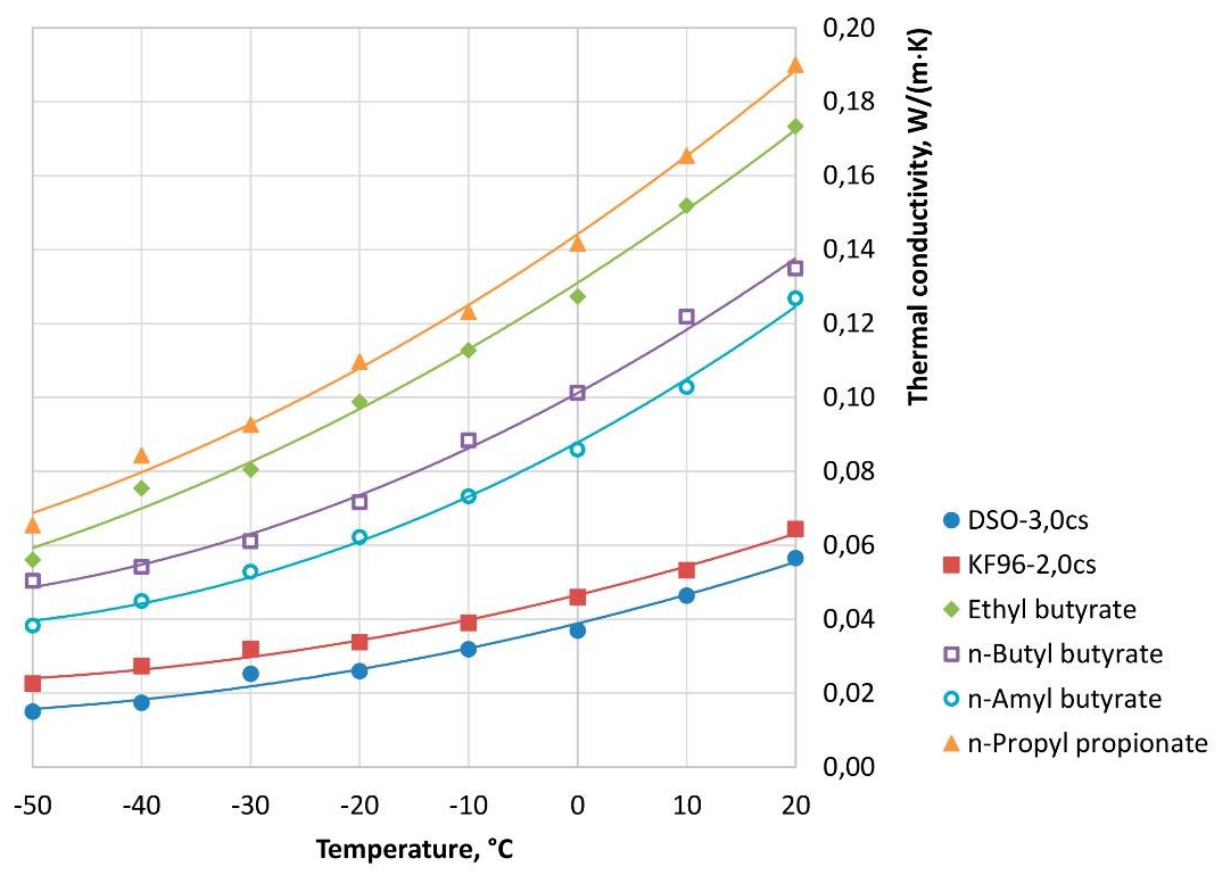

Fig. 4. Thermal conductivities of selected fluids vs temperatures 

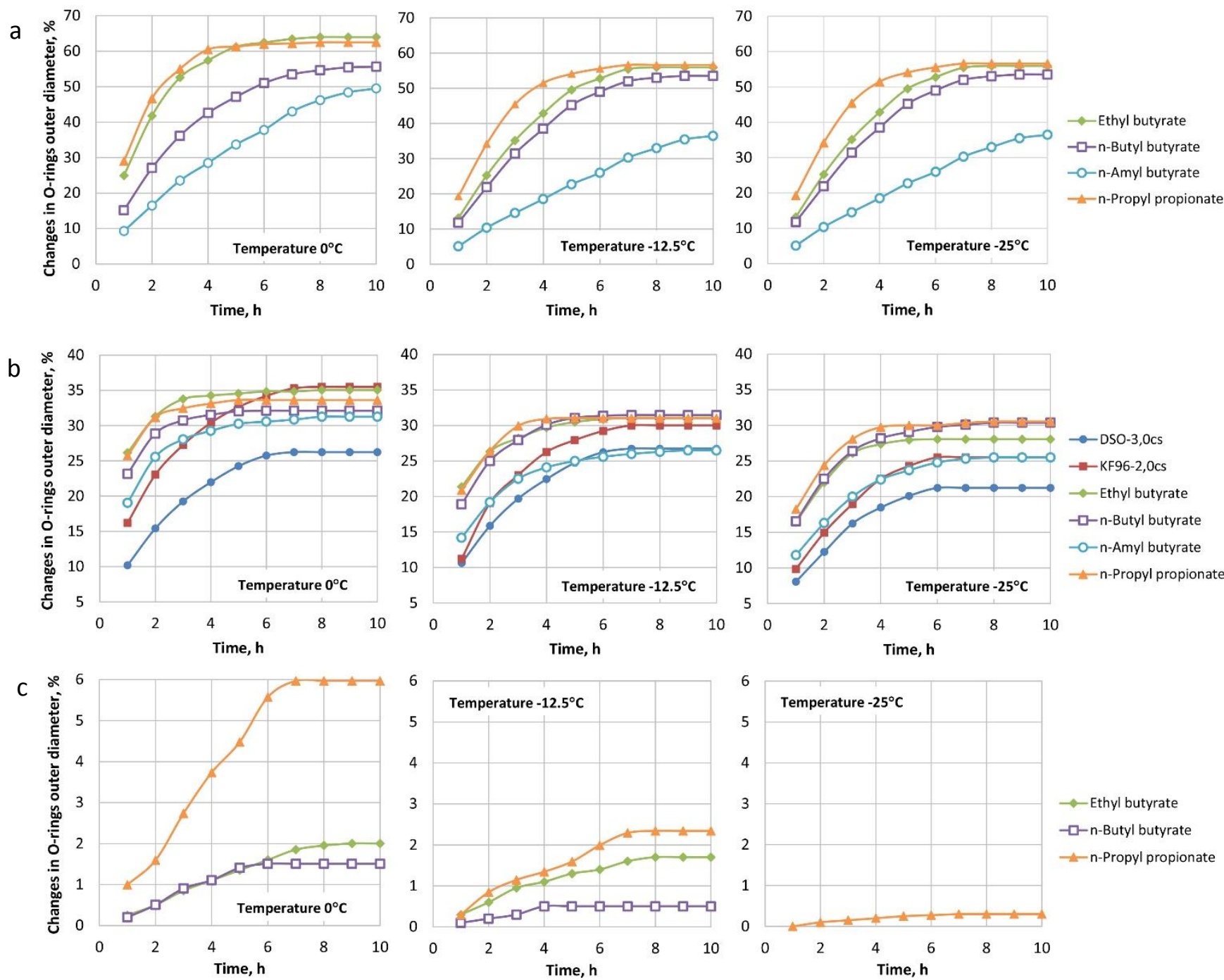

Fig. 5. Outer diameter changes [\%] vs time in 0-ring made from: a - fluorine rubber (fluorine rubber did not react with DSO-3,0cs and KF96-2,0cs); b - silicone rubber; c polyurethane (polyurethane did not react with DSO-3,0cs, KF96-2,0 cs and $n$-amyl butyrate at negative temperatures and with ethyl butyrate and $n$-butyl butyrate at temperature $\left.25^{\circ} \mathrm{C}\right)$ 
a

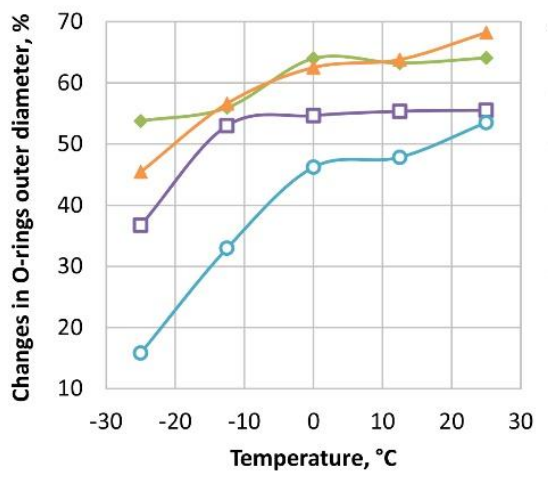

b

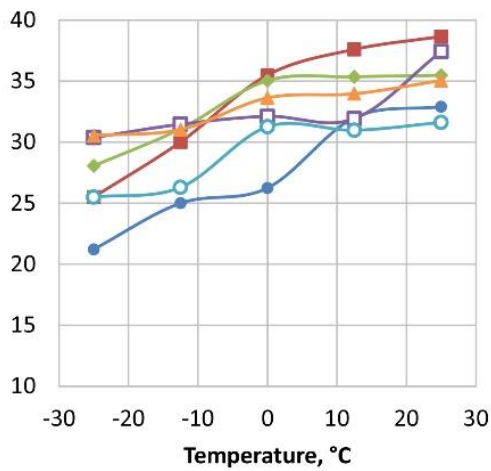

C

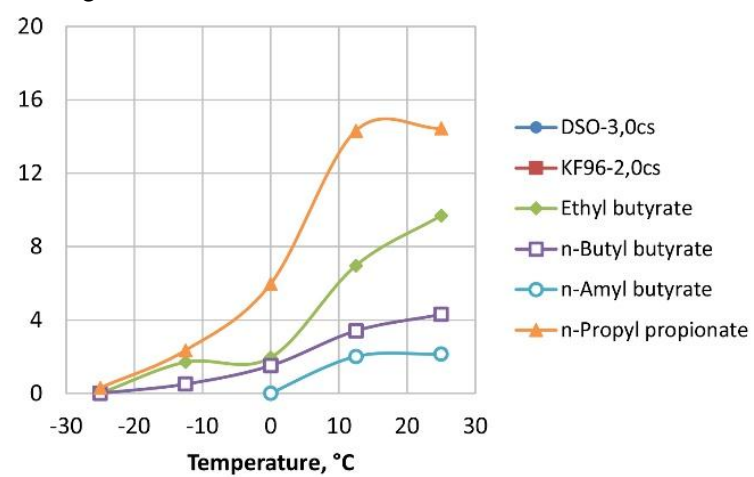

Fig. 6. Outer diameter changes [\%] vs temperature in 0-ring made from: a - fluorine rubber; $\mathrm{b}$ - silicone rubber; $\mathrm{c}$ - polyurethane after immersion in drilling fluids for $8 \mathrm{~h}$ 